\title{
Exploring nursing expertise in residential care for older people: A mixed method study
}

\author{
Amanda Phelan \& Brendan McCormack \\ Amanda PHELAN, Lecturer, Subject Head Older People, RN, MSc, PhD. \\ School of Nursing, Midwifery \& Health Systems, University College Dublin, Ireland. \\ Email: Amanda.phelan@ucd.ie \\ Phone: 0035317166482 \\ Twitter: @AmandaPhelan1
}

Brendan MCCORMACK, Professor of Nursing and Head of the Division of Nursing, RN, PhD. School of Health Sciences Queen Margaret University Musselburgh East Lothian.

Professor II, Buskerud and Vestfold University College, Drammen, Norway

Extraordinary Professor of Nursing, University of Pretoria, South Africa

Visiting Scholar, Dalhousie University, Halifax, Canada.

Acknowledgements: Thanks to the study participants for their time and interest.

Conflict of interests: No Conflict of interest has been declared by the author(s)

Funding statement: This study was funded by the All Ireland Gerontological Nurses' Association and Nursing Homes Ireland.

\section{Impact statement}

Within existing literature, there is a paucity of focus on nursing expertise in residential care. This paper is important as it offers multiple lenses within which the value of nursing expertise in residential care is manifested. Such expertise leads to better resident experience of care, leadership in nursing, and optimises person centred care outcomes through the intrinsic combination of knowledge and skill in practice. This study offers essential understandings based on multiple data sources and argues for the value of expert nurses and the importance of their unique, skilled contribution to positive outcomes in residential care environments.

\section{Abstract}

Aims: To explore the expertise of registered nurses in residential care for older people.

Background: As older people in residential care have many complex dependencies, nursing expertise is an essential component of care excellence. However, the work of these nurses can be invisible and therefore unrecognized. Thus, additional attention is required to illuminate such nursing expertise. 
Design: A mixed method design was used in this study

Methods: The research took place in 2012 in the Republic of Ireland. Twenty three case study nurses were recruited from nursing homes. Each case study nurse involved five data collection methods: Shadowing, interview with a colleague, interview with a resident, a demographic profile and a Director of Nursing survey. The study was also informed by a modified focus group. Qualitative data were analysed using directed content analysis using a conceptual framework generated from the literature on nursing expertise. Quantitative data were analyzed using SPSS and presented in descriptive statistics.

Findings: The findings from the case studies and the modified focus group are presented in seven themes which represent nursing expertise in residential care of older people: transitions, context of the nursing home, saliency holistic practice knowledge, knowing the resident, moral agency and skilled know how.

Conclusion: Nursing expertise in residential care of older people is a complex phenomenon which encompasses many aspects of care delivery within a person centred framework. By rendering this expertise visible, the need for appropriate and adequate skill mix for a growing residential care population is presented.

\section{Summary Statement}

\section{Why is this research or review needed?}

- The ageing population is rising globally with an increased demand for quality based care services

- Older people in residential care have multiple and complex individual histories, which demands expertise.

- Nursing expertise in residential care has been rendered invisible and many studies have not offered an indepth understanding of the necessary knowledge and skill inherent in such everyday practice.

\section{What are the key findings?}

- Expertise in nursing in residential care involves the combination of complex domains of knowledge and skill.

- This knowledge and skill is operationalized in everyday practice and includes the dimension of helping residents adjust to the residential care and immersion in the individual context of the nursing home

\section{How should the findings be used to influence policy/practice/research/education?}

- The findings demonstrate that nurses' everyday practice is often taken for granted, but is enmeshed in the complex blending of many forms of 
knowledge. Additional research should further investigate the expertise in this area to increase understandings of such expertise both within the broad domain of the nursing profession and for policy makers.

- As populations of older people rise in residential care, careful consideration should be given to skill mix as the registered nurse's expertise can often be devalued and rendered invisible. Person centred care quality outcomes should be the prerogative in residential care rather than cost containment or profit.

Keywords: Older people, Nursing home care, Case study research, Long-term care, Art of nursing.

\section{INTRODUCTION}

As life expectancies rise globally and the percentage of older populations increase, the demand for residential care will grow. Global populations of older people are expected to rise from 841 million, in 2013 to over two billion, in 2050 (United Nations 2013). Care demands for older people can be complex, (McDonald et al. 2015) and consequently, older people in residential care are amongst the most vulnerable within aged populations and therefore require expert nursing care.

\section{BACKGROUND}

As people age, the possibility of requiring supportive care systems increases. Many older people who require care live at home and receive support from family, friends and statutory services. However, although older people generally wish to remain in their own homes (National Institute on Aging 2010), as dependency increases, the fragile thresholds of these supportive services may mean admission to residential care. While both community and residential care models have advantages, both also have disadvantages. For instance, while supportive services may be limited in the home environment, 
moving to residential care means having to adjust to communal living (Rosen et al. 2008).

Residential care facilities are also known as nursing homes, aged care facilities, care homes with nursing/without nursing, group homes and long term care for older people. There are a number of catalysts that influence admission to residential care, such as increasing dependency, being admitted for respite, recuperation or rehabilitation or being admitted for end of life care (Spilsbury et al. 2011). Factors such as gender, home support, acute care provision and geographical supply and demand can also impact on residential care admission (Wren 2009). Moreover, models for residential care vary due to historical and cultural influences, national support, regulatory standards and intergenerational solidarity (Daly \& Szebehely 2012).

In residential care, the need for expertise is fundamental to quality care (Mezzy et al. 2005). A distinguishing feature of nursing in residential care is residents become 'like family members' (Casey et al. 2011:1825). A study by Heath \& AIGNA (2010) demonstrates the expansion of nurses' skills in response to care needs. This includes co-ordinating multi-disciplinary teams, nurse prescribing, and roles in clinical specialisms and advanced nursing practice. Despite the need for expert nursing, working in aged care has not enjoyed a high status (Bass 2011) with recruitment and retention being challenged in this sector (Castel \& Engberg 2006, Castle et al. 2007, Heath \& AIGNA 2010). In an effort to address these challenges, some organisations have recruited staff of lower grades (deBellis 2010, Heath 2012) leading to a blurring of roles and the invisibility of the nurse's expertise (Karlsson et al. 
2009,). Moreover, it has also been suggested that this perceived invisibility has contributed to the agenda of reducing ratios of registered nurses in residential care (RCN 2004). Studies have demonstrated tacit differences between registered nurses and health care assistants; registered nurses have greater responsibilities in care provision related to accountability, responsibility and holistic care provision (Parquay et al. 2007, Heath \& AIGNA 2010). Thus, having the appropriate complement of registered nurses who have competencies related to care of older people underpins positive care experiences.

The concept of person centred care is well in care of older people and most regulatory frameworks support these principles (HIQA, CQC, Scottish Care Commission, Federal Nursing Homes Regulations). Person-centredness can be defined as:

' $\ldots$ an approach to practice established through the formation and fostering of healthful relationships between all care providers, service users and others significant to them in their lives. It is underpinned by values of respect for persons, individual right to self-determination, mutual respect and understanding. It is enabled by cultures of empowerment that foster continuous approaches to practice development.' (McCormack et al., 2013, p 193)

In nursing homes, it is essential for staff to facilitate each resident's personhood (Maher \& Harley 2015). Such care is co-created through humanistic dialogue that fosters the individual's sense of self and promotes social connectiveness (Cooney et al. 2009, McGilton et al. 2012). Thus, residential care facilities are transformed to places where older people can flourish (McCormack et al. 2011) and where nursing expertise is valued (McCormack \& Titchen 2001). 
Nursing expertise involves the development of competencies where a nurse moves from technical rationality to professional artistry (Hardy et al. 2009, Petty et al. 2012). Professional artistry is 'the meaningful expression of a uniquely individual view with a shared tradition' (Manley et al. 2005: 26). However, nurses can struggle to define the context of expertise in their practice due to being embodied in their professional self-identity (Lyneham et al. 2008, Heath \& AIGNA 2010). Early work by Benner (1984), using Dreyfus and Dreyfus's (1980) work, described the progression from novice to expert. An expert is considered to practice intuitively, can generate a vision and adapt experiential knowledge to situations. The expert nurse is able to integrate multiple knowledge domains such as empirics, ethics, knowledge of self and aesthetics (Carper 1978). Practice is consequently not rule bound but nurses become rule reformers where complex challenges in practice are addressed (Lynehan et al. 2008), through skilled companionship (Titchen 2001). Such practice is also recognised by professional peers, which establishes the expert nurse as authoritative and trustworthy (Manley et al. 2005). This nursing expertise impacts on improved care outcomes and enhanced care quality (Heath \& AIGNA 2010).

Expertise within gerontological nursing is difficult to define as it encompasses core nursing skills but also a knowledge of the ageing process, the impact of ageing on the older person and the implementation of person centred care approaches (Webster 2009). Consequently, this study sought to address the invisibility of registered nurses' expert practice in residential care by illuminating the constituent elements of gerontological nursing and how such 
expertise is manifested within daily interactions with older people and colleagues.

\section{THE STUDY}

\section{Aim}

This study aimed to explore the expertise of registered nurses in residential care for older people.

\section{Design}

In order to develop knowledge of the expertise involved in nursing older people in residential care, a triangulated approach was taken to develop a descriptive, multi-case design.

\section{Research question}

What constitutes an expert registered nurse in residential care of older people?

\section{Conceptual Framework}

Manley and McCormack (1997) propose specific domains for nursing expertise: holistic practice knowledge, saliency, knowing the patient, moral agency and skilled know how (table 1). These domains provide the conceptual framework for this study. 
Table 1: Conceptual framework of expertise in nursing: Domains and attributes (Phelan \& McCormack 2013, adapted from Manley \& McCormack 1997)

\begin{tabular}{|c|c|}
\hline $\begin{array}{l}\text { Holistic practice } \\
\text { knowledge }\end{array}$ & $\begin{array}{l}>\text { Using all forms of knowledge. } \\
\text { Ongoing learning and evaluation from new } \\
\text { situations. } \\
\text { Drawing from a range of knowledge bases to inform } \\
\text { practice. } \\
>\text { Embedding new knowledge and accessing in similar } \\
\text { situations. }\end{array}$ \\
\hline Saliency & $\begin{array}{l}\text { Discriminating cues to inform the situation. } \\
\text { Observation of non-verbal cues to understand the } \\
\text { individual's own situation. } \\
\text { Listening and responding to verbal cues. } \\
\text { Regarding the patient as a whole to inform practice. } \\
\text { Ability to recognise the needs of the patient, } \\
\text { colleagues and others in actions taken. }\end{array}$ \\
\hline Knowing the Patient & $\begin{array}{l}>\text { Respect for people and their perspectives } \\
>\text { Respecting perspectives of the patient on his/her } \\
\text { illness or life world } \\
>\text { Willing to promote and maintain a person's dignity at } \\
\text { all times. } \\
>\text { Conscious use of self to promote a helping } \\
\text { relationship. } \\
>\text { Promoting the patient's own decision making } \\
>\text { Willingness to relinquish 'control' to the patient. } \\
>\text { Recognizing the patient's /other's expertise }\end{array}$ \\
\hline Moral agency & $\begin{array}{l}>\text { Providing information to enhance people's ability to } \\
\text { problem solve and make decisions on their on behalf } \\
>\quad \text { Consciously working to promote another person's } \\
\text { dignity, respect and individuality. } \\
>\quad \text { Conscious awareness of one's work and behaving } \\
\text { impeccably. } \\
>\text { Working and living own values and beliefs, while } \\
\text { respect other's values and beliefs }\end{array}$ \\
\hline Skilled know how & $\begin{array}{l}\text { Enabling others through a willingness to share } \\
\text { knowledge and skills. } \\
>\text { Adapting and responding with careful regard to } \\
\text { individual situations. } \\
>\text { Mobilizing all available resources. } \\
>\text { Envisioning and articulating a plan through a } \\
\text { problem/situation and inviting others to participate in } \\
\text { the plan. }\end{array}$ \\
\hline
\end{tabular}

Settings and Participants

The study took place in the Republic of Ireland (henceforth referred to as 'Ireland'). At the time of the study's data collection (2012), Ireland had 565 designated centres for older person care, with a maximum bed capacity of 29,060. Of this number, 75 percent (465) were described as being privately operated, 20.5 percent (115) were run by the state (The Health Service 
Executive [HSE]) with the remaining 4.5 percent (25) being operated by bodies funded by the HSE (HIQA 2015).

Participants were recruited through advertisements within HSE networks and through e-mails to the All Ireland Gerontological Nurses' Association (AIGNA) and Nursing Homes Ireland's membership listings. Directors of Nursing (DON) across state, private and voluntary sector nursing homes were invited to volunteer their residential care facility to participate. Criteria for self-selection were that the case study nurse must be registered with the Irish Nursing and Midwifery Board and that they had a minimum of one year's experience working in residential care for older people.

\section{Sample}

A total of 23 DONs and 4 individual nurses expressed interest in the study. One nurse withdrew interest and two nurses indicated that their DON did not support the study. One DON withdrew due to emergent staffing issues. The remaining 23 sites agreed to participate in the study: 6 were public HSE facilities, 14 were privately managed facilities and 3 were voluntary run nursing homes. Each of the 22 DONs who volunteered recruited a registered nurse to participate who met the selection criteria and these names were forwarded to the research team. The nurse who self-selected obtained relevant permission from her DON and the researchers initiated contact. Each 'case study nurse' was contacted by the research team to elicit their agreement to participate. Twenty-three case study nurses participated and each represented a context sensitive unit of analysis (Patton 2002). 


\section{Data collection}

Six data collection methods were used in this study. Data collection occurred over a 12-month period. Five data collection methods were used with each of the 23 case study nurses, while a modified focus group explored the essential elements within expertise in gerontological nursing (figure 1).

Figure 1: Data collection methods (Phelan \& McCormack 2013)

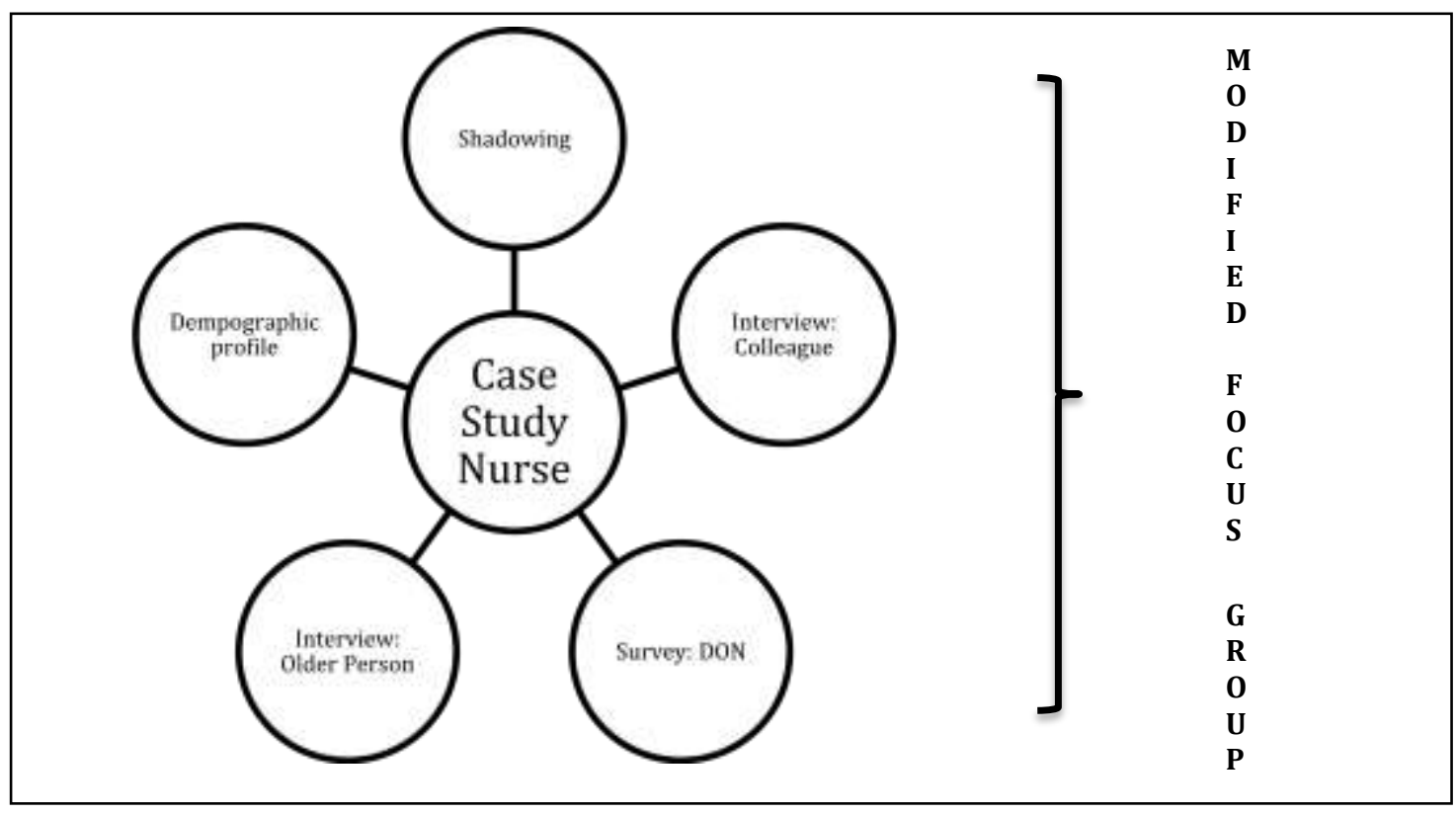

A description of five case study nurse specific data methods is presented in table 2. 
Table 2: Participants and method type for case study nurse

\begin{tabular}{|c|c|}
\hline Participant & Method type \\
\hline $\begin{array}{l}\text { Case study nurse }(n=23) \\
\text { (all female) }\end{array}$ & $\begin{array}{l}\text { Shadowing (Smith 1987): Derived from institutional } \\
\text { ethonography, this data collection method involved } \\
\text { accompanying the case study nurses for the duration } \\
\text { of two and a half hours. Copious notes were taken } \\
\text { detailing interactions with older residents, colleagues } \\
\text { and family members. Shadowing periods occurred } \\
\text { between } 8.00 \text { am- } 12.00 \text { midday, with one shadowing } \\
\text { period being } 13.30-16.00\end{array}$ \\
\hline $\begin{array}{l}\text { Case study nurses } \\
\text { demographic survey } \\
(n=23)\end{array}$ & $\begin{array}{l}\text { Quantitative survey: Six questions based on age, } \\
\text { length of time working with older people, employment } \\
\text { contract hours, number of residents on the unit } \\
\text { worked in, specialized older person education or } \\
\text { training and level of education or training. }\end{array}$ \\
\hline $\begin{array}{l}\text { Interview: Nurse colleague }(n=23) \\
\text { Health care assistant }(n=11) \\
\text { Registered nurse }(n=12)\end{array}$ & $\begin{array}{l}\text { Semi-structured interviews: Directed by topic guide } \\
\text { based on experience of working with the case study } \\
\text { nurse and how expertise is operationalized (Duration } \\
\text { range: } 40-60 \text { minutes) }\end{array}$ \\
\hline $\begin{array}{l}\text { Interview: Older person } \\
(\mathrm{n}=23) \\
\text { Female }(\mathrm{n}=18) \\
\text { Male }(\mathrm{N}=5)\end{array}$ & $\begin{array}{l}\text { Semi-structured interviews: The DON approached } \\
\text { suitable older residents and discussed the study a } \\
\text { minimum of two weeks prior to the researcher's visit } \\
\text { to the nursing home. After informed consent, the DON } \\
\text { provided the older resident's name to the researcher } \\
\text { and formal written consent occurred. Interviews were } \\
\text { guided by a topic guide based on nursing home } \\
\text { admission and the experience of care from the case } \\
\text { study nurse. (Duration } 30-50 \text { minutes) }\end{array}$ \\
\hline $\begin{array}{l}\text { Director of Nursing survey } \\
(n=23)\end{array}$ & $\begin{array}{l}\text { Qualitative survey: Based on the case study nurse. } \\
\text { Using open-ended questions based on Hardy et al. } \\
\text { (2009). Section one contained six questions based on } \\
\text { describing the case study nurse in the context of her } \\
\text { expertise. Section two contained three questions } \\
\text { which requested examples of how such expertise was } \\
\text { practically operationalized. }\end{array}$ \\
\hline
\end{tabular}

The modified focus group occurred at the AIGNA Annual Conference.

Delegates were invited to participate and the session was moderated by the study researchers. Participants were divided into 13 sub-groups containing 8-

10 people each. The composition is represented in table 3. 
Table 3: Composition of modified focus group

\begin{tabular}{|l|c|}
\hline \multicolumn{1}{|c|}{ Role } & Number \\
\hline Residential care nursing managers & 62 \\
\hline Clinical nurse specialists in older person care & 3 \\
\hline Registered general nurses working in older person care & 30 \\
\hline Practice development staff working in older person care & 4 \\
\hline $\begin{array}{l}\text { Staff from the Health Information and Quality Authority (HIQA)(Regulatory } \\
\text { and inspection body) }\end{array}$ & 2 \\
\hline Managing Director/Person in Charge & 2 \\
\hline Other Staff (Social Worker or administrators) & 12 \\
\hline TOTAL & $\mathbf{1 1 5}$ \\
\hline
\end{tabular}

The researchers identified components related to expert nursing in residential care of older people using the study conceptual framework. Each focus group was allocated a particular issue to discuss and asked to describe how this would be operationalized in practice. Each group nominated a note-taker and the moderators traversed each group to assist with any concerns or queries. Groups presented their deliberations and the group notes were collected by the researchers. Both researchers also recorded notes during the final large group discussion.

\section{Ethics}

Ethical approval for this study was granted by the University Research Ethics Committee. For HSE facilities, ethics was obtained from the Assistant National Director for Services for Older People. For private or voluntary facilities, individual ethical approval was obtained. All information about the study was provided to staff and residents two weeks before the researcher collected data. Individual interview and survey participants gave written informed consent. For the shadowing activity, the case study nurse gave written informed consent and all residents who were within the practice area gave oral informed consent to the DON prior to the researcher's visit which 
was recorded and the researcher confirmed and recorded this consent with the older residents immediately prior to undertaking the observation. For older people who had cognitive impairment and were unable to provide informed consent, consent was sought from a family member or the DON.

For the modified focus group, all delegates at the AIGNA conference were given a participant information sheet in their delegate packs and invited to participate. During the conference, participants were given the choice of attending the modified focus group or a workshop on a gerontological topic. Consent was given by virtue of opting to participate.

\section{Data analysis}

The qualitative data (shadowing, interviews, DON survey and modified focus groups) were inputted into Nvivo10@. Analysis was undertaken using direct content analysis (Hsieh \& Shannon 2005, Pistang \& Barker 2010). This method allowed the researchers to validate and extend existing research on the topic of nursing expertise in residential care of older people. Consequently, pre-selected themes were identified using the conceptual framework and cross-checked against other work in this field (Manley et al. 2005, Hardy et al. 2006). In the analysis of the data, our findings did not exclusively fit into these predetermined themes of expertise and this led to the generation of two additional themes which were embedded in the datacontext and transitions. Firstly, a new theme called 'Context of the nursing home' allowed the idea of communities of practice (Wenger 2000) to emerge and reflected localised expertise within the complex organisation of the 
nursing home. This theme also facilitated acknowledgement that the expert nurse is enmeshed in a particular social, political and environmental milieu with many personal and professional interconnections. The second theme developed (Transitions) was specifically related to a resident's admission to the nursing home and how this transition was assisted by the expert nurse.

Data from the demographic profile were inputted into SPSS v18 and presented as descriptive findings. The data were firstly examined in relation to the five data components for each individual case study nurse. Following this, a review and consolidation of all data was undertaken, integrating the modified focus group data and developing robust exemplars of nursing expertise in residential care of older people.

\section{Rigour}

In this study, rigour was addressed in several ways. Dependability of the qualitative data collection methods was addressed through robust discussion and preparation of each of the data collection methods by the researchers. Transcriptions were checked against recordings on a number of occasions to ensure fidelity, while the shadowing phase produced copious notes specifying the activities of the case study nurse. Coding was discussed by both researchers and inter-rater agreement was achieved (Patton 2002). The use of Nvivo10@ allowed precise and transparent decision making and a clear decision trail for the final themes (Welch 2002). Using deductive directed content analysis, the themes are valid as they captured what was intended (Schreier 2012) though a theory based categorisation matrix, while the two additional themes were generated through an inductive process, which was 
agreed by both researchers. For the modified focus groups, data were recorded by each focus group and submitted to the researchers, thus ensuring accuracy. A triangulation of the data methods also increased dependability as individual data generation methods complemented each other. The demographic data were inputted into SPSS v18 and presented as descriptive statistics based on categorical variables.

\section{RESULTS}

The results of this study were originally reported in Phelan and McCormack (2013). This paper reports on specific findings from the study that highlight particular characteristics of nurse experts in residential care settings.

The case studies had a broad national geographical distribution. Within the demographic profiles, almost 35 percent of the participants were aged between 22 years and 30 years. Most participants were full time employees $(n=18)$, most of whom worked in residential care units of 11-30 residents $(\mathrm{N}=11)$. Seven of the case study nurses worked with older people for $1-3$ years while another 7 worked with older people for over 10 years. Three worked with older people for between 4-6 years and 6 for 7-10 years. In relation to education or training specific to gerontology, table 4 presents the findings for the case study nurse participants.

Table 4: Education/Training in gerontology and level

\begin{tabular}{|c|c|}
\hline $\begin{array}{c}\text { Education/Training in gerontology and } \\
\text { level }\end{array}$ & Case study nurse \\
\hline Education days (CPD) & 17 \\
\hline Certificate level & 8 \\
\hline Diploma & 3 \\
\hline Degree & 1 \\
\hline Post Graduate & 4 \\
\hline Did not respond & 1 \\
\hline
\end{tabular}




\section{The expert nurse in residential care}

Seven themes are presented: transitions, context of the nursing home, saliency, holistic practice knowledge, knowing the resident, moral agency and skilled know how.

\section{Transitions}

During the older person interviews, it was apparent how the transition to a nursing home was traumatic for the older person. The decline in health status meant living at home became too challenging as exemplified in the excerpt below from one of the residents:

I fell too often...I fell out of the bed and [when] I was trying to walk outside, I would fall. [OP1]

In one shadowing experience (2), the nurse spoke of how a resident had had a series of cardio vascular attacks and had 'given up' on admission, so she made a determined effort to constantly encourage the older person to utilise his residual potential. The need for psychological support is also evident as the admission could be perceived as particularly stressful, which required ongoing support over a period of time:

It is another chapter in your life, really and truly, you sort of say, here am I now, leaving a home, leaving everything and I am helpless. I have to depend on people. [OP23]

Thus, part of nursing expertise is to help residents to adjust to their new circumstances. This transcends the physical care related to medical diagnosis, to paying attention to the psychological trauma of perceived loss of independence and of connection to his/her previous life on admission to residential care. 
Context of the nursing home

This theme emerges from the ideas of communities of practice where knowledge is shared and belonging to a group who have mutual goals (Wenger 2002). Thus, nurses do not work in an ideological or practice vacuum, but within complex networks of relationships. This was exemplified by a consideration of traits required for such specific practice:

I would say definitely it [nursing in residential care] requires skills because you are looking after vulnerable people so there are definitely skills that you have to have to do that. [NC 13)

This involved the nurse developing careful relationships with residents and other staff to generate knowledge of individual residents in order to optimise positive care outcomes:

She [nurse] established a relationship of trust with the residents and their families which allows for better information gathering and sharing. Nurse $X X X$ also used information received from care assistants to develop her care plans. [DON 4]

Consequently, the expert nurse is immersed in a system within which they contributed to the overall organisation of care, such as taking leadership roles:

[Nurse] is involved in the clinical governance committee in the home. She is a link nurse with the pharmacy, ensuring high quality medication management. [Nurse] is developing her role as link nurse for 'end of life care' within the home. [DON 5]

The interconnections of the expert nurse were evident in all the data forms. For example, findings from the modified focus group spoke of ' knowing when to ask for help and recognising each other's [colleagues] skills so that optimum care is achieved'.

Thus, the expert nurse could not be isolated from the contextual environment of practice. They work within a definite community of practice where meaning 
is shared over time. Through exploring this category, the research highlighted the expert nurses practice related to the social order of the residential care home and the data provided understandings in areas such as values, ways of doing things, attitudes and ethos.

\section{Saliency}

Saliency involves examining how the expert nurse uses skills related to picking up on and responding to cues in daily practice. Within the tacit practice observed in shadowing (1), the nurse was caring for a very ill resident and observed the fabric of the nightdress was unsuitable as it promoted perspiration and could impact on skin integrity. While carefully removing the nightdress, the nurse gently assisted with bathing the resident and checked the skin for signs of pressure risk before checking the bedclothes for dampness and creases. After drying the skin, she assisted the resident to dress in a cotton nightdress and ensured a comfortable position. The nurse was visibly seen to check the resident's face for signs of pain or discomfort while also asking if pain was being experienced. Throughout the interaction, the resident was treated with positive regard, respect and dignity. This individualised way of interacting was inquiring in terms of not only looking at what might be happening but critically appraising the antecedents to what was being observed.

Another example is where a nurse colleague commented on a person centred project the case study nurse initiated which resulted in the reducing one resident's aggressiveness:

...I just find with one lady who would be quite aggressive in the mornings, like this role play that we have started with her quite recently, it is like a break through. [NC14] 
Saliency could also extend to work colleagues as one DON observed:

[Nurse] showing concerns regarding colleagues going through difficult [situations] outside [work]. Advised them who to speak to. [DON 2]

Saliency, as the focus group observed, could encompass knowing the skill of gathering information and recognising the progress of sickness in an older person rather than [just] picking up the 'classic signs'. Saliency was the skill of discrimination of what precisely matters in a situation and being able to respond to the presenting encounter.

\section{Holistic practice knowledge}

Expert nursing depends on the integration of multiple knowledge forms to optimise therapeutic responses. Active engagement in reflective practice, continuous personal and professional development and an ethos of lifelong learning are central to holistic practice and leadership. One nurse colleague describes holistic practice knowledge in practice in the excerpt below:

She [nurse] has a very good knowledge of wounds and dressing, palliation...she just looks at the total care picture... just absolutely everything, she is fantastic [NC 18]

Such holistic knowledge is also recognised by residents with a high degree of confidence in positive outcomes derived from the nurse's advice.

She's [nurse] sharp...she notices the difference...I can trust [name], no reflection on the other nurses, but I think [name] is that bit more, maybe she feels she can give instructions but anytime [name] comes to see the wounds, I know I am going to get a proper result or verdict [OP 3]

Within the context of shadowing, all of the 23 case study nurses demonstrated holistic practice knowledge and in one case (shadowing 3 ), one of the researchers made the annotation of 'symphony of care delivery', which used 
the simile of an orchestra co-creating music. Thus, holistic practice knowledge represents the synthesis of knowledge, relational availability and the capacity to non-problematically apply and adapt to new situations.

\section{Knowing the resident}

A central part of person-centredness is personhood. This was apparent in all the nurses' actions and verbal communication. Such an approach to care was recognised by DONs, nursing colleagues and the residents. For instance, one

DON observed:

When addressing the resident's care plan, the nurse discusses all care with the resident and encourages choice and reminds the resident that is about them being a person and not what others may expect from them. [DON 17]

Knowing the resident also meant that friendly banter could occur between the nurse and resident. The following encounter was witnessed in shadowing 6 and illuminates such a conversation:

Ah...I am a contrary old bag...[OP6]

Well, I suppose you are from [names county], you can be contrary 'cause you lost the All Ireland [National Football championship] [Nurse]

Both laugh

Knowing the resident also extended to picking up subtle changes in the resident. One resident recalled such an observation when the nurse observed a possible kidney infection:

Yes, she [Nurse] would take a specimen straight away and she could do it herself and then if it was a severe infection they would ring $\mathrm{Dr}$. $\mathrm{X}$ to know what tablets to put me on. There is every care taken, every care. [OP 20]

Thus, knowing the resident translated to knowledge of the life history of the resident, their usual presentation and would often also include knowledge of their family. 
Moral agency

Moral agency was evidenced through careful communication strategies that promoted the self-determination of residents, respected individuality, promoted dignity and demonstrated value and respect for one's own beliefs and those of others. There were examples of how this occurred in practice in all of the data sources.

Yes she would give you all the facts around the case that would be very classic now, she will never be at a loss, she will cover the solution or her proposed solution, she won't be at a loss, she will give you all the facts of it rather than saying, oh I don't know, she is this. [NC9]

Within the focus group, findings identified that the expert nurse practices with dignity and respect, and is inherently immersed in person centred care.

\section{Skilled know how}

Being able to lead and adapt appropriately to situations and mobilising the appropriate resources for individual situations underpinned the skilled know how of the expert nurse.

...she can deal with the emerging situation effortlessly, for example deescalate a resident's aggression [DON 7]

Skilled know how was admired by colleagues who had confidence in the nurse's ability to advise.

And she [Nurse] thought of that before... not looking bad on myself but she'd be a step ahead sometimes and l'd be like, thanks a million. I was getting to that in a little while but it was sorted, she might have it done on a Friday and l'd be thinking of it on a Monday or whatever. [NC6]

Thus, the application of skilled know how also maximised the potential for positive care outcomes and inspired confidence in colleagues and management. 


\section{DISCUSSION}

The invisibility of nurses' practice in residential care of older people is well documented (RCN 2004, Hardy et al. 2006, Heath 2012). Consequently, there is an urgent need to recognise and support nursing expertise and practice in this area (Tolson et al. 2011, McGilton 2012). This study has demonstrated the subtle meaning of expertise in the everyday practice of the 23 case study nurses. In delivering care, each nurse demonstrated multiple yet complex practice qualities that cohered to produce expertise. While, such practice appeared ordinary in the context of everyday work, it is transformed into extraordinary when all elements of the data were analysed. Such expertise presents a cogent argument against the reduction of registered nurses in residential care of older people. Indeed, this argument is strengthened by the emphasis on the necessity of quality person centred care from policy directives (HSE 2013, Maher \& Harley 2015), the increasing demand of such services in the future (Wren et al. 2012) and the fact that frailty levels in

residential care have increased in the last ten years (McGregor \& Roland 2011). In a recent paper, Eldh et al. (2015) highlighted registered nurses satisfaction with their role working in nursing homes, highlighting the bonds formed with residents, professional autonomy and capacity for learning and growth as key experiences. Our study adds further insights to the work of Eldh et al. (2015) as it specifically illuminates how registered nurses working in nursing homes use knowledge, skills and expertise to create such satisfaction for themselves and residents. 
The mixed methodological approach had the advantage of offering different perspective on expertise. Data were produced from the perspective of an ethnographic approach (shadowing) where expertise was witnessed in action. The impact of such expertise does not occur in a vacuum, thus, the recognition of the case study nurses' expertise was also presented from three different sources: colleagues, management and most importantly, the older residents. Without fail, all sources demonstrated particular attributes and domains of care expertise, which were supported by the modified focus group. Finally, the demographic profiles gave an insight into the individual background of the case study nurses. However, contrary to Benner's (1984) assertion that expertise involves practice of a minimum of five years, this study demonstrated expertise could occur in a shorter period of time. Thus, expertise may not be time bound and in this study, the case study nurse's personal motivational traits have exemplified expertise with an overwhelming common characteristic of being in a specialism they loved and being immersed in a community of practice that fosters such expertise development. Thus, the social capital of the environment cannot be separated from the development of expertise. Such communities of practice are fluid with a symbiotic relationship of the nurse with her colleagues. Consequently, situated learning occurs where the nurse both learns from and teaches colleagues. Wenger (1998) sees this as mutual engagement, a joint enterprise and the development of a shared repertoire.

Data were aligned to the existing general framework of nursing expertise based on Manley and McCormack (1997), Manley et al. (2005) and Hardy et al. (2006). All of the case study nurses demonstrated leadership, a person 
centred focus, authentic presence (McCormack \& McCance 2010) and relational availability (Boscart 2010). However, specific to the environment of residential care, two further themes were generated pertaining to the admission to the nursing homes and how the nurse practices within the context of residential care. These two additional themes offer situational and experiential findings that further exemplify residential care nursing expertise.

A final point of note relates to the tension of fiscal priorities and quality care provision. Although time and cost constraints did not emerge as findings in this study, appropriate staffing and skill mix are essential to facilitate the time and opportunity to deliver expertise. Without this, omitted care is likely and this has significant impacts on staff retention, teamwork and the quality of care (Kalisch et al. 2013).

\section{Limitations}

The shadowing activity may have impacted on how the case study nurse practiced (Hawthorne effect), however, attempts to limit this were to engage in conversation about residents to reduce anxiety and to discuss activities in the context of being typical of their routine practice. Moreover, all case study nurses were female, therefore a gender bias was present. In addition, the residents who were interviewed only represented a proportion of the total resident population as they were recruited by the DON (who may have favoured particular residents) and they all had cognitive ability and were semiindependent. Those with greater dependency may have different experiences. In addition, other data sources could have been generated such as perspectives of resident's relatives and friends, the independent advocates in 
Irish nursing homes or a review of official HIQA reports of the residential care facility. Finally, the self-selection of nursing homes may have led to a bias wherein DONs who were confident in the care excellence in their nursing home volunteered. This was somewhat validated as some DONs, case study nurses or the nursing colleagues often mentioned very positive inspection and regulation reports.

\section{CONCLUSION}

This research has illuminated nursing expertise in residential care and findings have implications beyond this study's findings. As the population of older people rises globally, it is important that residential care is not reduced to simple tasks and providing care to older people is seen as requiring particular expertise for positive outcomes. This means that, both within and outside the nursing profession, practice is valued and that the need for appropriate and adequate skill mix should not be overly focused on cost containment, but on enhanced person centred outcomes. In this way, global ageing populations can have confidence in residential facilities that provide quality care experiences that promote individual personhood. While this study has demonstrated the uniqueness of nursing expertise in residential care, further research is necessary to further explicate the capabilities of nurses in this setting, particularly in relation to reducing the blurring of nursing roles and those of health care assistants, reducing the invisibility of this expertise and increasing the professional status of this sector. 


\section{REFERENCES}

Bass D.D. (2011) Experiences of registered nurses as managers and leaders in residential care facilities: a systemic review. International Journal of Evidence Based Healthcare 9, 388-402.

Benner, P (1984) From novice to expert: excellence and power in clinical nursing practice. Menlo Park CA, Addison-Wesley.

Boscart V. (2010) The development of a nurse-patient relationship scales in chronic care. Unpublished PhD thesis, University of Toronto.

Casey D., Murphy K., Ni Leime A., Larkin P., Payne S., Froggatt K.A. \& O'Shea E. (2011) Dying well: factors that influence the provision of good endof-life care for older people in acute and long-stay settings in Ireland. Journal of Clinical Nursing 20, 1824-1833.

Carper B.A. (1978) Fundamental patterns of knowing in nursing. Advances in Nursing Science 1, 13-23.

Castle N.G. \& Engberg J. (2006) Organisatioinal characteristics associated with staff turnover in nursing homes. The Gerontologist, 46(1), 62-73.

Castle N.G., Engberg J. \& Men A. (2007) Nursing home staff turnover: Impact on nursing home compare quality measures. The Gerontologist, 47(5), 630661.

Cooney A., Murphy K., O'Shea E. (2009) Resident perspectives of the determinants of quality of life in residential care in Ireland. Journal of Advanced Nursing 65(5), 1029-1038.

Daly T. \& Szebehely M. (2012) Unheard voices, unmapped terrain: care work in long term residential care for older people in Canada and Sweden, International Journal of Social Welfare 21, 139-148.

deBellis A. (2010) Australian residential aged care and the quality of nursing care provision. Contemporary Nurse 35(1), 100-113.

Dreyfus, S.E. \& Dreyfus, H.L. (1980) A five stage model of mental activities involved in directed skill acquisition. Unpublished Report. University of California (Berkley).

Eldh A.C., van der Zijpp T., McMullan C., McCormack B., Seers K and Rycroft-Malone J (2015) "I Have The World's Best Job" - Staffs' Experience of Advantages in Caring for Older People. Scandinavian Journal of Caring Sciences. [Epub ahead of print] Retrieved from http://www.ncbi.n/m.nih.gov/pubmed/26265314 on August $15^{\text {th }}$ 2015. doi: $10.1111 /$ scs. 12256 
Hardy S., Titchen A., Manley K. \& McCormack B. (2006) Re-defining nursing expertise in the United Kingdom. Nursing Science Quarterly 19(3), 260-264.

Hardy S., Titchen A., Manley K. \& McCormack B. (2009) A final turn of the kaleidoscope. In Revealing nursing expertise through practitioner inquiry (Hardy S., Titchen A., McCormack B. \& Manley K. eds), Wiley-Blackwell, Chichester, pp 55-74.

Health Information \& Quality Authority (2015) Annual overview report on the regulation of designated centres for older people-2014. HIQA, Dublin.

Health Service Executive (2013) Person centred care and support: supporting services to deliver quality healthcare. HSE, Dublin.

Heath H. \& AIGNA (2010) The role and contribution of the registered nurse in residential care settings for older people in Ireland: a national survey. Research for the All Ireland Gerontological Nurses' Association. AIGNA, Cork.

Heath $\mathrm{H}$. (2012) How to optimise the registered nurse contribution in care homes. Nursing Older People 24(2), 23-28.

Hsieh H.F. \& Shannon S.E. (2005) Three approaches to qualitative content analysis. Qualitative Health Research. 15, 1277-1288.

Kalisch B.J., Lee K.H., Doumit M. \& El Zein J. (2013) Missed nursing care, level of staffing and job satisfaction. Journal of Nursing Administration, 43(5), 274-279.

Karlsson I., Ekman S.L., \& Fagerberg I. (2009) A difficult mission to work as a nurse in a residential care home- some registered nurses' experiences of their work situation. Scandinavian Journal of Caring Sciences 23, 265-273.

Lyneham J., Parkinson C. \& Denholm C. (2008) Explicating Benner's concept of expert practice: intuition in emergency nursing. Journal of Advanced Nursing 4(4), 380-37.

Maher S. \& Harley D. (2015) It's all about people and relationships: Scotland's persons centred health and care collaborative. International Journal of Integrated Care. Annual Conference Suppl.; URN:NBN:NL:UI:10-1-116982.

Manley K., Hardy S., Titchen A., Garbett R. \& McCormack B. (2005) Changing patients' worlds through nursing practice expertise. RCN Institute, London.

Manley K. \& McCormack B. (1997) Exploring expert practice (NUM65U). RCN, London.

McCormack B., Carragher L., Coyle A., Bond R. (2011) Places to flourish: a pattern based approach to foster change in residential care. HSE, Dublin. 
McCormack B. \& McCance T. (2010) Person centred nursing; theory and practice. Wiley-Blackwell, Chicester.

McCormack B., McCance T. \& Maben J (2013) Outcome Evaluation in the Development of Person-centred Practice. In Practice Development in Nursing (Vol 2) (McCormack B., Manley K. \& Titchen A. eds.), Wiley-Blackwell Publishing, Oxford, pp. 190-211

McCormack B. \& Titchen (2001) Patient centred practice: an emerging focus for nursing expertise. In Practice, knowledge and expertise in the health professions (Higgs J. \& Titchen A. eds), Butterworth-Heinemann, Oxford, pp 96-101.

McDonald L., Sheppard C., Hitzg S.L., Spalder T., Mathur A. \& Singh Mukhi J. (2015) Resident to resident aggression: A scoping review. Canadian Journal on Aging 34(2), 215-236.

McGilton K.S. (2012) Editorial: The role of the nurse in long-term care. International Journal of Older People Nursing 7, 282-283.

McGilton K.S., Heath H., Chu C.H., Boström A.M., Mueller C., Boscart V.M., McKenzie-Green B., Moghabghab R. \& Bowers B. (2012) Moving the agenda forward: A person centred framework in long term care. International Journal of Older People Nursing 7, 303-309.

McGregor M.J. \& Roland L.A. (2011) Residential long term care for Canadians seniors: No-profit, for profit or does it matter? IRPP study No. 14, Institute for Research on Public Policy, Montreal.

Mezzy M., Greene-Burger A., Bloom A.G., Bonner A., Bourbonniere M., Bowers B., Burl J.B., Capezuti A., Carter D., Dimant J., Jerro S.A., Reinhard S.C. \& Ter Maat M. (2005) Experts recommend strategies for strengthening the use of advanced practice nurse in nursing homes. Journal of the American Geriatrics Society, 53, 1790-1797.

National Institute on Aging (2010) There's no place like home for growing old. NIA, Gaithersburg.

Parquay L., De Lepeleire J. \& Milisen K. (2007) Tasks performance by registered nurse and care attendants in nursing homes: a quantitative comparison of survey data. International Journal of Nursing Studies, 44(8), 1459-1467.

Patton M.Q. (2002) Qualitative research and evaluation methods. $3^{\text {rd }}$ edn., Sage Publications, Thousand Oaks.

Petty N.J., Thompson O.P. \& Stew G. (2012) Ready for a paradigm shift? Part 1: introducing the philosophy of qualitative research. Manual Therapy 17, 267274. 
Phelan A. \& McCormack B. (2013) Exploring nursing expertise in residential care of older people in Ireland. AIGNA \& NHI, Dublin.

Pistang N. \& Barker C. (2010) Scientific, practical and personal decisions in selecting qualitative methods. In Developing and delivering practice based evidence. (Barkham M., Hardy G.E. \& Mellor-Clark J. eds), Wiley-Blackwell, Chicester, pp 6590.

Rosen T., Lachs M., Bharucha A.J., Stevens S.M., Teresi J.A., Nebres F. \& Pillemer K. (2008) Resident-to-resident aggression in long-term care facilities: insights from focus groups of nursing home residents and staff. Journal of the American Geriatric Society 56(8), 1398-1408.

Royal College of Nurses (2004) Nursing assessment and older people: $A$ Royal College of Nursing toolkit, RCN, London.

Schreier M. (2012) Qualitative content analysis in practice. Sage, London.

Spilsbury K., Hewitt C., Stirk L. \& Bowman C. (2011) The relationship between nurse staffing and quality of care in nursing homes: a systematic review. International Journal of Nursing Studies 48(6), 732-750.

Titchen A. (2001) Skilled companionship in professional practice. In Practice, knowledge and expertise in the health professions. (Higgs J. \& Titchen A. eds.), Butterworth-Heinemann, Oxford, pp 69-79.

Tolsen D., Roland Y., Andrieu S., Aquino J.P., Beard J., Benetos A., Berrut G., Coll-Planas L., Dong B., Forette F., Franco A., Franzoni S_Salvà, A., Swagerty D., Trabucchi M., Vellas B., Volicer L. \& Morley J.E. (2011) International Association of Gerontology and Geriatrics: A global agenda for clinical research and quality of care in nursing homes. Journal of the American Medical Directors Association 12(3), 184-189.

United Nations (2013) World population ageing. UN, New York.

Webster J. (2009) Expertise in practice-older people. In Revealing nursing expertise through practitioner inquiry (Hardy S., Titchen A., McCormack B., \& Manley K. eds.), Wiley-Blackwell, Chichester, pp 128-149.

Welsh, Elaine (2002). Dealing with Data: Using NVivo in the Qualitative Data Analysis Process [12 paragraphs]. Forum Qualitative Sozialforschung / Forum: Qualitative Social Research, 3(2), Art. 26 Retrieved from http://nbnresolving.de/urn:nbn:de:0114-fqs0202260 on Feburary $11^{\text {th }} 2014$.

Wenger E. (1998) Communities of practice learning: learning, meaning and identity. Cambridge University Press, New York.

Wenger E. (2000) Communities of practice and social learning systems, Organisation. 7(2), 225-246. 
Wren, M.A. (2009) Long-Term Health and Social Care. In Projecting the Impact of Demographic Change on the Demand for and Delivery of Health Care in Ireland. Research Series Number 13, (Layte R. ed.) Economic and Social Research Institute, Dublin, pp 100-126.

Wren M.A., Normand C., O'Reilly D., Cruise S.M., Connolly S. \& Murphy C. (2012) Towards the development of a predictive model of long-term care demand for Northern Ireland and the Republic of Ireland. Centre for Health Policy and Management, TCD, Centre for Public Health, QUB, and the Irish Centre for Gerontology, NUI, Galway. 